\title{
Efeito alelopático e análise dos rótulos de garrafadas comercializadas no Mercado Municipal de Montes Claros - MG
}

\author{
MARQUES, J.O.'; OLIVEIRA, M.F.F.'; LACERDA, G.A.1,** \\ ${ }^{1}$ Faculdade de Saúde Ibituruna - FASI, Avenida Nice, $n^{\circ}$ 99, Bairro Ibituruna, CEP: 39401-303, Montes Claros \\ - MG, Brasil. 'Universidade Estadual de Montes Claros - UNIMONTES, Campus Universitário Darcy Ribeiro, \\ Vila Mauricéia, CEP: 39401-089 Montes Claros-MG, Brasil. *Autor para correspondência: guilhermebiologia@ \\ yahoo.com.br
}

\begin{abstract}
RESUMO: O presente estudo teve como objetivo analisar o efeito alelopático e o rótulo dos produtos vegetais contidos nas garrafadas comercializadas no mercado municipal de Montes Claros - MG. Adquiriram-se oito garrafadas que foram utilizadas para tratar, cada uma, 20 sementes de alface (Lactuca sativa L.) dispostas em placas de Petri sobre papel saturado com $4 \mathrm{~mL}$ do conteúdo de cada garrafada em 04 concentrações: 12,$5 ; 25 ; 50$; e $75 \%$. O controle positivo foi realizado com solução de sulfato de zinco a $1 \%$, além dos controles: água mineral, água da torneira, e água destilada. As placas de Petri foram lacradas com filme plástico, cobertas com saco plástico e incubadas em escuro por sete dias à temperatura média de $27,2^{\circ} \mathrm{C}$ e na umidade média de $54 \%$. Após 7 dias, mediu-se o comprimento da radícula e do hipocótilo $(\mathrm{mm})$ de cada uma das plântulas e quantificou-se o número de sementes que germinaram. Os dados foram submetidos à análise de variância pelo software Sisvar, sendo os resultados comparados pelo Teste Scott-Knott ao nível nominal de 5\%. Os resultados do teste de germinação indicaram que houve efeito significativo das garrafadas sobre a germinação das sementes de Lactuca sativa L., onde o percentual de germinação das sementes foi inversamente proporcional ao aumento da concentração das garrafadas. Portanto, observou-se que as garrafadas apresentaram potencial alelopático ao inibirem a germinação das sementes de alface.
\end{abstract}

Palavras-chave: alelopatia, plantas medicinais, rotulagem de produtos, alface.

\begin{abstract}
Allelopathic effect and analysis of bottle labels commercialized in the municipal market of Montes Claros - MG. This study aimed to analyze the allelopathic effect and label of plant products put in bottles commercialized in the municipal market of Montes Claros - MG. Eight bottles were employed to treat, each one, 20 lettuce seeds (Lactuca sativa L.) placed at Petri plaques over saturated paper with $4 \mathrm{~mL}$ of the content of each bottle in 04 concentrations of $12.5 ; 25 ; 50 ; 75 \%$ for each bottle, $1 \%$ of zinc sulfate solution (positive control) and 3 negative control groups (containing mineral water, tap water and distilled water). The Petri plaques were sealed with plastic film, covered with plastic bag and incubated in the dark for seven days at an average temperature of $27.2^{\circ} \mathrm{C}$ and average humidity of $54 \%$. After 7 days, it was measured the length of the radicle and the hypocotyl $(\mathrm{mm})$ of each one of the seedlings and the number of seeds that germinated was quantified. The data were submitted to analysis of variance by Sisvar software and the results were compared by Scot-Knott Test at a nominal level of $5 \%$. The results of the germination test indicated that there was a significant impact of the bottles in the germination of the lactuca sativa L. seeds, where the percentage of seeds germination was inversely proportional to the concentration increase in the analyzed bottles. Therefore, it has been observed that the bottles presented allelopathic potential when they inhibited the germination of lettuce seeds.
\end{abstract}

Keywords: allelopathy, medicinal plants, product labeling, lettuce.

Rev. Bras. PI. Med., Campinas, v.17, n.4, supl. III, p.1134-1141, 2015. 


\section{INTRODUÇÃO}

A medicina popular, proveniente dos tempos da antiguidade, ainda é prática viva e generalizada na era contemporânea (Nogueira, 2005). Estudos sobre a medicina popular vêm merecendo atenção cada vez maior devido ao contingente de informações e esclarecimentos que vêm sendo oferecido à Ciência (França et al., 2007). Na medicina popular encontramos a onipresença das famosas "garrafadas", produtos artesanais destinados ao tratamento, ou prevenção, de enfermidades (Souza Filho, 2011).

As garrafadas podem ser consideradas herdeiras das velhas triagas, fórmulas secretas conhecidas dos reis, físicos e sacerdotes que as usavam, desde a mais remota antiguidade. Porém, hoje, cabe aos raizeiros, erveiros e curandeiros indicados pela comunidade tradicional, que, as manipulam. Questiona-se, porém, quando o termo "triaga" foi substituído no meio popular, por garrafada (Camargo, 2011). De acordo com Carreira \& Santos (2001) o termo garrafada surgiu em Portugal nos séculos XVI, XVII e XVIII relacionando-se ao vinho associado a plantas medicinais, no Brasil utilizado como panacéia, um catalizador.

Garrafadas, designativo de derivado vegetal (Brasil, 2010) de uso entre brasileiros que recorrem à medicina popular (Camargo, 2011), são preparações constituídas da combinação de plantas medicinais, com finalidade específica, tendo como veículo água, aguardente ou vinho branco (Siqueira \& Higino, 2008). São inúmeras as variedades de ervas medicinais utilizadas nas garrafadas e de outros complementos (Dantas et al., 2008), como elementos de origem animal e mineral.

As substâncias das plantas medicinais utilizadas podem ter interações entre elas apresentando determinada toxicidade ao organismo e, consequentemente reações adversas. A utilização de bioensaios vegetais para o monitoramento de substâncias ou frações de compostos isolados de plantas é uma excelente ferramenta, sendo desenvolvida com sementes de espécies sensíveis (Noldin et al., 2003) capazes de demonstrar efeito tóxico.

A alelopatia pode ser definida como a interferência positiva ou negativa de compostos metabólicos secundários produzidos por uma planta (aleloquímicos) e lançado no meio (Souza et al., 2007). Muitas substâncias químicas presentes nos vegetais podem levar ao surgimento de um efeito alelopático, o qual se refere à capacidade que as plantas têm de interferir na germinação de sementes e no desenvolvimento de outras (Souza et al., 2005). Os efeitos indiretos incluem alterações nas propriedades e características nutricionais do solo e, também, nas populações ou atividades de organismos (De Conti \& Franco, 2011).

Os testes de toxicidade são uma metodologia de uso rotineiro. Apesar de não apontarem as substâncias químicas responsáveis pela contaminação, expressam os verdadeiros efeitos que uma combinação de compostos pode exercer sobre os organismos, incluindo os efeitos aditivos, antagônicos e sinérgicos.

Os bioensaios de toxicidade aguda avaliam os efeitos sofridos pelos organismos expostos aos agentes químicos, que podem afetar o desenvolvimento normal das plantas, principalmente nas suas etapas iniciais como germinação, em um curto período de tempo, em geral de um a quatro dias. Ao observar e medir o comprimento de raízes jovens e comparar estas medidas com um controle positivo, como um metal pesado como o Zinco (Machado et al., 2009) seria possível fazer a suposição da presença de compostos químicos tóxicos.

A alface (Lactuca sativa L.) é uma das hortaliças herbáceas mais consumidas no mundo e no Brasil, agronomicamente muito delicada, de caule diminuto não ramificado (Nascimento et al., 2012). Segundo os mesmos autores, a principal vantagem do uso da alface nos estudos alelopáticos reside na sensibilidade da espécie, mesmo em baixas concentrações de aleloquímicos. Além disso, a espécie demonstram outras peculiaridades que favorecem sua utilização: germinação rápida, em aproximadamente $24 \mathrm{~h}$; crescimento linear insensível às diferenças de $\mathrm{pH}$ em ampla faixa de variação e insensibilidade aos potenciais osmóticos (Souza et al., 2005).

A partir do bioensaio utilizando sementes de alface, pode-se inferir a possível presença de substâncias químicas com ação tóxica. Esta estaria em hipótese relacionada ao manejo incorreto das plantas medicinais desde a plantação a colheita. Manejo em locais contaminados, ou a até mesmo a presença de fertilizantes nas garrafadas, o que também pode representar perigo, se consumido pelo ser humano.

Neste contexto, este trabalho teve como objetivo analisar o efeito alelopático dos preparados, contidos em algumas garrafadas comercializadas no Mercado Municipal de Montes Claros - MG, na germinação das sementes de alface (Lactuca sativa L.), bem como supor uma possível toxicidade das garrafadas analisadas.

\section{MATERIAL E MÉTODO}

As garrafadas foram adquiridas no mercado municipal de Montes Claros - MG, onde foram escolhidas oito garrafadas comercializadas (Tabela

Rev. Bras. PI. Med., Campinas, v.17, n.4, supl. III, p.1134-1141, 2015. 
1) que possuíam rótulos de identificação, critério de inclusão, sendo a ausência de rótulo, critério de exclusão. As 08 amostras de garrafadas adquiridas são comercializadas em diversas bancas de plantas medicinais do local.

\section{Teste de germinação}

Colocou-se em cada placa de Petri (90x15 $\mathrm{mm}$ ) um papel filtro J. Prolab $® \mathrm{com} 11 \mathrm{~cm}$ de diâmetro (Adaptada de Araújo \& Monteiro, 2005 e RAS, 2009). Em seguida, cada placa foi identificada, data de inicio e término do experimento, e com a diluição e amostra correspondente. Ao todo foram utilizadas 44 placas sendo 8 garrafadas $\times 5$ concentrações $(12,5 \%=0,5 \mathrm{~mL} ; 25 \%=1 \mathrm{~mL} ; 50 \%=2 \mathrm{~mL} ; 75 \%=3 \mathrm{~mL}$ e $100 \%=4 \mathrm{~mL}(\mathrm{v} / \mathrm{v}))=40$ placas (sem repetições), 1 com o controle positivo - solução de Sulfato de zinco $\left(\mathrm{ZnSO}_{4}\right)$ a $1 \%$ (Machado et al., 2009) e outras 3 com os controles negativos (CN). Nossos CNs foram água mineral (diluente com constituição mencionada pelo fabricante), água da torneira (abastecimento local) e água destilada (solvente universal) como o objetivo de também compará-los. Em cada placa, o papel de filtro foi saturado com $4 \mathrm{~mL}$ das amostras com água mineral anteriormente (Adaptada de Araújo \& Monteiro, 2005), e em seguida, com a ajuda de uma pinça, foram colocadas em cada uma delas, de modo equidistante, 20 sementes de alface comercial sem defensivo (Lactuca sativa L. variedade botânica: Repolhuda todo ano).

Em seguida, foram lacradas com filme plástico, para que não houvesse perda da umidade. Depois, foram cobertas com saco plástico e incubadas em escuro por sete dias à temperatura média de $27,2^{\circ} \mathrm{C}$ e umidade média de $54 \%$ (verificadas por um termo-higrômetro digital Incoterm ${ }^{\circledR}$ modelo 7666.02.0.00). seguindo-se recomendações do fabricante

Após 7 dias foram medidas cuidadosamente com o auxílio de um paquímetro, o comprimento da radícula e do hipocótilo $(\mathrm{mm})$ de cada uma das plântulas correspondente a cada diluição, e dos controles positivo e negativos. Em seguida, observaram-se o número de sementes que germinaram.

\section{Análise estatística}

O experimento foi instalado segundo um delineamento inteiramente casualizado com 20 sementes em que esquema fatorial com amostras de oito garrafadas e cinco tipos de concentrações 12,5; 25; 50; 75; $100 \%$ (v/v), além dos Controles Negativos (CN): água mineral, água da torneira e água destilada, e do Controle Positivo: Sulfato de Zinco $\left(\mathrm{ZnSO}_{4}\right)$ a $1 \%$.

Os dados foram submetidos à análise de variância pelo software Sisvar (Ferreira, 2000), sendo os resultados obtidos comparados pelo Teste Scott-Knott ao nível nominal de $5 \%(p=0,0005)$.

\section{Análise dos rótulos}

A foram avaliados segundo a adequabilidade de rotulagem, de acordo com os dados que constam na Resolução RDC n 26, de 13 de maio de 2014 (Brasil, 2014).

\section{RESULTADO E DISCUSSÃO}

A composição de cada garrafada está descrita no Tabela 1 de acordo com o indicado em cada frasco, porém a identificação das espécies botânicas mencionadas nos rótulos das garrafadas não foi possível, sem percentual dos veículos utilizados, devido a estas apresentarem somente os nomes populares das plantas utilizadas nos preparos das mesmas. As concentrações de cada planta medicinal também não foram informadas pelos fabricantes, bem como as partes botânicas utilizadas na preparação dos extratos.

Os eventos de crescimento vegetal devemse principalmente ao aumento no número e/ou o alongamento celular, enquanto o desenvolvimento refere-se a processos de diferenciação como a germinação (Brasil, 2009). Os resultados do teste de germinação indicaram que houve um efeito significativo $(p=0,0005)$ das amostras das garrafadas sobre a germinação das sementes de Lactuca sativa L. (Tabela 2), ao serem comparadas à solução de sulfato de zinco a $1 \%$ (controle positivo) que é tóxica para as sementes interferindo diretamente na germinação e crescimento das mesmas. O percentual de germinação das sementes é inversamente proporcional ao aumento das concentrações das concentrações das garrafadas analisadas.

Constatou-se que as garrafadas $1,2,3$, 4,5 e 7 na concentração de $12,5 \%$ e, 4 e 7 na concentração de $25 \%$ apresentaram resultados semelhantes estatisticamente (valor- $p=0,0005)$ a germinação ocorrida nos controles negativos, onde foram empregados três tipos de água (mineral, torneira e destilada), sendo que as garrafadas 4 e 7 na concentração de $25 \%$ apresentaram um percentual de germinação, igual ou maior que $80 \%$, maior que qualquer uma das águas utilizadas como controle, e evidenciou-se que a mineral (macro e micronutrientes) é a mais favorável para a germinação das sementes, dentre as utilizadas no experimento. Porém as garrafadas 6 e 8 demonstraram efeito negativo para as sementes, inibindo completamente a germinação em todas as concentrações avaliadas.

O controle positivo demonstrava aspeto de protrusão radicular e posterior morte das plântulas

Rev. Bras. PI. Med., Campinas, v.17, n.4, supl. III, p.1134-1141, 2015. 
TABELA 1. Composição e indicações mencionadas nos rótulos das garrafadas utilizadas no bioensaio de toxicidade aguda com sementes de alface (Lactuca sativa L.).

\begin{tabular}{|c|c|c|c|}
\hline Garrafada & Composição vegetal & Outras composições & Indicação de uso* \\
\hline 1 & $\begin{array}{l}\text { Catuaba**, Jurubeba, Jurema-preta, Pau- } \\
\text { ferro, Prá-tudo, Semente-de-ginseng e } \\
\text { Casca-de-jenipapo }\end{array}$ & $\begin{array}{l}\text { Vitaminas } A, B, D \text { e } \\
E \text {, cálcio e magnésio }\end{array}$ & $\begin{array}{l}\text { Doenças crônicas; osteoporose; osteíte; } \\
\text { osteomielite; periosteíte e dores na coluna. }\end{array}$ \\
\hline 2 & $\begin{array}{l}\text { Confrei, Barbatimão, Velame-do-campo, } \\
\text { Escada-de-macaco, Chapéu-de-couro, } \\
\text { Verbênia, Camomila }\end{array}$ & & $\begin{array}{l}\text { Regulação do sistema urinário feminino; } \\
\text { menstruações difíceis e com dores; } \\
\text { inflamações no útero e ovários; corrimento; } \\
\text { blenorragia; ardor na vagina; cólicas; } \\
\text { uretrite e doenças venéreas. }\end{array}$ \\
\hline 3 & $\begin{array}{l}\text { Batata-jalapa, Erva-de-bicho, Hortelã miúdo, } \\
\text { Semente-de-abóbora, Mastruz indiano, } \\
\text { Boldo-do-chile, Babosa e Óleo-de-palma- } \\
\text { criste }\end{array}$ & & $\begin{array}{l}\text { Contra lombriga, oxiúros, caseiras pretas } \\
\text { e brancas, ancilóstomo, tênia de porco, } \\
\text { tênia de boi, xistossomo e outros vermes. } \\
\text { E ainda contra ameba e giárdia. }\end{array}$ \\
\hline 4 & $\begin{array}{l}\text { Jatobá, Piúva, Cainana, Cipó-caboclo, } \\
\text { Anis-estrelado, Emburana, Boldo-do-chile, } \\
\text { Ipê-roxo, Carqueja, Jutaicí, Angico, Noz- } \\
\text { moscada, Jurubeba, Alecrim, Velame-do- } \\
\text { campo, Cavalinha, Pau-ferro, Barbatimão, } \\
\text { Paripiroba, Pulga-do-campo }\end{array}$ & Própolis & $\begin{array}{l}\text { Tratamento da coluna; distúrbios } \\
\text { renais; digestivos; azia; gastrite; úlcera; } \\
\text { furunculose; prisão de ventre; câncer de } \\
\text { próstata; angina no peito; artrite; artrose; } \\
\text { gota; câncer; doenças do fígado, baço e } \\
\text { colesterol alto. }\end{array}$ \\
\hline 5 & $\begin{array}{l}\text { Barbatimão, Camomila, Algodoeira, Velame- } \\
\text { do-campo, Aroeira, Agoniada, Folha-de- } \\
\text { verbena, João-da-costa }\end{array}$ & & $\begin{array}{l}\text { Menstruação irregular; inflamação do } \\
\text { ovário; dores, cólica do útero; clorose; } \\
\text { atomias;, combate a afecções estéricas; } \\
\text { ardor vaginal, corrimento, blenorragia } \\
\text { (gonorreia), bexiga e regulador do sistema } \\
\text { urinário. }\end{array}$ \\
\hline 6 & $\begin{array}{l}\text { Abacateiro, Chá-verde, Carqueja, Chapéu- } \\
\text { de-couro, Jambolão, Cavalinha, Melissa, } \\
\text { Douradinha, Salsa-parrilha, Erva-de-bugre, } \\
\text { Carobinha, Sene, Dente-de-leão, Funcho, } \\
\text { Cidreira, Sete-sangria, Hibisco, Graviola, } \\
\text { Fucus, Cáscara-sangrada, Maracujá, }\end{array}$ & Colágeno & $\begin{array}{l}\text { Gordura localizada; celulite; estrias; } \\
\text { ansiedade; varizes; digestivo; reumatismo } \\
\text { e palpitação do coração; diurético; } \\
\text { depurativo e calmante; colesterol; } \\
\text { diabetes; ácido úrico; prisão de ventre. }\end{array}$ \\
\hline
\end{tabular}

Fucus, Cáscara-sangrada, Maracujá, Espinheira-santa, Quebra-pedra, Boldodo-chile, Jurubeba, Angélica, Pau-ferro, Cajueiro, Centelha-asiática, Alcachofra, Malva-branca, Porangaba, Velame, Juá, Sucupira, Ipê-roxo, Jatobá

7 Espinheira-santa, Alcachofra-do-norte, Artemísia, Carqueja-amarga, Castanhada-índia, Cavalinha, Chapéu-de-couro, Ipê-roxo, Jurubeba, Salsa-parrilha

Vergateza, Catuaba, Marapuama, Nó-decachorro, Canela, Imburana, Nó-de-cola, Ginseng, Pra-tudo
Vinho licoroso (veículo***)
Gastrite; úlcera, pedra nos rins; fígado; hepatite; circulação; ácido úrico; pressão alta; varizes; reumatismo; prisão de ventre; hemorroidas; vermífugo; controle de diabetes; regimes de emagrecimento.

Antissifilítico; antiasmático; antianêmicos; diuréticos; mau funcionamento dos rins, fígado, baço, vesícula, intestinos; gripe; reumatismo; fraqueza dos nervos, sexual e cérebro; doenças de senhoras e inflamação de próstata.

\footnotetext{
*Todas as indicações constavam nos rótulos sem as devidas referências. **As grafias foram alteradas para nomenclatura usual com hífen. ***Não foi citada a concentração utilizada para veículo na amostra 8.
} 
(Machado et al., 2009) possivelmente a toxicidade do Zinco em relação a semente de alface.

Resultados díspares foram obtidos por Pelegrini \& Cruz-Silva (2012) testando o efeito alelopático de Coleus barbatus, conhecido como falso-boldo, na germinação de sementes de alface, constando que não houve a inibição da germinação da alface, com 4 repetições. De Conti et al. (2011), testaram os extratos de raiz e caule de Casearia sylvestris, e nenhuma das concentrações testadas inibiu significativamente a germinação das sementes de alface.

Entretanto, Alves et al. (2011), obtiveram resultados semelhantes aos desse trabalho, os quais observaram que Tabernaemontana catharinensis e Tithonia diversifolia possuem um maior efeito inibitório na germinação de Lactuca sativa quando utilizados em maiores concentrações. Magiero et al. (2009) observaram que extratos de Artemisia annua nas concentrações de $50 \%$ e acima houve total inibição da germinação das sementes de alface. Mesmo com metodologias diferentes obtiveram resultados semelhantes.

Bonfim et al. (2011) evidenciam o efeito alelopático de melissa e hortelã sobre o desenvolvimento de plântulas de tanchagem, determinado pelo comportamento germinativo das sementes. $O$ extrato das cascas do caule e fruto de Tamarindus indica, bem como as folhas frescas inibiram a emergência das plântulas de alface segundo estudo de Nascimento et al. (2012).

O tamanho das radículas e dos hipocótilos também foi afetado significativamente pelas amostras menos diluídas das garrafadas (Tabelas 3 e 4).

Em relação ao efeito dos controles negativos sobre o tamanho das radículas, nenhuma das amostras obteve resultados estatisticamente semelhantes (Tabela 3), o que indica que as garrafadas em quaisquer concentrações são extremamente tóxicas para o crescimento das radículas e podem ser comparadas com o controle positivo.

Não foram observados efeitos morfo-

TABELA 2. Comparação da porcentagem de germinação (\%) das sementes de alface submetidas às concentrações das amostras das garrafadas identificadas com rótulo e comercializadas no Mercado Municipal de Montes Claros, MG, Brasil, 2014.

\begin{tabular}{llllllllll}
\hline \hline \multirow{2}{*}{ Garrafada } & \multicolumn{6}{l}{ Concentrações das Amostras } & \multicolumn{7}{c}{ Controles } & & \\
& $12,5 \%$ & $25 \%$ & $50 \%$ & $75 \%$ & $100 \%$ & CNAD & CNAT & CNAM & CP \\
\hline 1 & $65 \mathrm{~b}$ & $75 \mathrm{a}$ & $20 \mathrm{a}$ & $0 \mathrm{a}$ & $0 \mathrm{a}$ & & & & \\
2 & $85 \mathrm{~b}$ & $0 \mathrm{a}$ & $0 \mathrm{a}$ & $0 \mathrm{a}$ & $0 \mathrm{a}$ & & & & \\
3 & $65 \mathrm{~b}$ & $10 \mathrm{a}$ & $5 \mathrm{a}$ & $0 \mathrm{a}$ & $0 \mathrm{a}$ & & & & \\
4 & $85 \mathrm{~b}$ & $95 \mathrm{~b}$ & $10 \mathrm{a}$ & $0 \mathrm{a}$ & $0 \mathrm{a}$ & $80 \mathrm{~b}$ & $80 \mathrm{~b}$ & $85 \mathrm{~b}$ & $40 \mathrm{a}$ \\
5 & $60 \mathrm{~b}$ & $70 \mathrm{a}$ & $0 \mathrm{a}$ & $0 \mathrm{a}$ & $0 \mathrm{a}$ & & & \\
6 & $0 \mathrm{a}$ & $0 \mathrm{a}$ & $0 \mathrm{a}$ & $0 \mathrm{a}$ & $0 \mathrm{a}$ & & & \\
7 & $80 \mathrm{~b}$ & $100 \mathrm{~b}$ & $35 \mathrm{a}$ & $0 \mathrm{a}$ & $0 \mathrm{a}$ & & & \\
8 & $0 \mathrm{a}$ & $0 \mathrm{a}$ & $0 \mathrm{a}$ & $0 \mathrm{a}$ & $0 \mathrm{a}$ & & & \\
\hline
\end{tabular}

CNAD = controle negativo (água destilada); CNAT = controle negativo (água da torneira); CNAM = controle negativo (água mineral); CP = controle positivo (Sulfato de Zinco 1\%). Médias seguidas de mesma letra minúscula na linha não diferem entre si pelo teste de Scott-Knott a um nível nominal de significância de $5 \%$.

TABELA 3. Valores médios para comprimento da radícula $(\mathrm{mm})$ de sementes de alface (Lactuca sativa L.) segundo as concentrações das amostras das garrafadas comercializadas no Mercado Municipal de Montes Claros, MG, Brasil, 2014.

\begin{tabular}{|c|c|c|c|c|c|c|c|c|c|}
\hline \multirow{2}{*}{ Garrafada } & \multicolumn{5}{|c|}{ Concentrações das Amostras } & \multicolumn{4}{|c|}{ Controles } \\
\hline & $12,5 \%$ & $25 \%$ & $50 \%$ & $75 \%$ & $100 \%$ & CNAD & CNAT & CNAM & $\mathrm{CP}$ \\
\hline 1 & $1,50 \mathrm{a}$ & $1,35 \mathrm{a}$ & $0,10 \mathrm{a}$ & $0,00 \mathrm{a}$ & $0,00 \mathrm{a}$ & \multirow{8}{*}{26,33 e } & \multirow{8}{*}{$16,42 \mathrm{c}$} & \multirow{8}{*}{$22,09 d$} & \multirow{8}{*}{$0,40 \mathrm{a}$} \\
\hline 2 & 0,56 a & $0,00 \mathrm{a}$ & $0,00 \mathrm{a}$ & $0,00 \mathrm{a}$ & $0,00 \mathrm{a}$ & & & & \\
\hline 3 & $1,42 \mathrm{a}$ & $0,47 \mathrm{a}$ & $0,05 \mathrm{a}$ & $0,00 \mathrm{a}$ & $0,00 \mathrm{a}$ & & & & \\
\hline 4 & $10,19 b$ & $0,60 \mathrm{a}$ & $0,25 \mathrm{a}$ & $0,00 \mathrm{a}$ & 0,00 a & & & & \\
\hline 5 & $2,24 \mathrm{a}$ & $2,70 \mathrm{a}$ & $0,00 \mathrm{a}$ & $0,00 \mathrm{a}$ & $0,00 \mathrm{a}$ & & & & \\
\hline 6 & $0,00 \mathrm{a}$ & $0,00 \mathrm{a}$ & $0,00 \mathrm{a}$ & $0,00 \mathrm{a}$ & $0,00 \mathrm{a}$ & & & & \\
\hline 7 & $3,85 a$ & $2,10 \mathrm{a}$ & $1,01 \mathrm{a}$ & $0,30 \mathrm{a}$ & 0,00 a & & & & \\
\hline 8 & $0,00 \mathrm{a}$ & $0,00 \mathrm{a}$ & $0,00 \mathrm{a}$ & $0,00 \mathrm{a}$ & $0,00 \mathrm{a}$ & & & & \\
\hline
\end{tabular}

CV\% $=198,05 ;$ CNAD = controle negativo (água destilada); CNAT = controle negativo (água da torneira); CNAM = controle negativo (água mineral); $\mathrm{CP}=$ controle positivo (Sulfato de Zinco 1\%). Médias seguidas de mesma letra minúscula na linha não diferem entre si pelo teste de Scott-Knott a um nível nominal de significância de 5\%. 
genéticos ou contaminações na germinação das sementes em relação aos controles positivos para as variáveis comprimento da radícula e hipocótilo $(\mathrm{mm})$.

Oliveira et al. (2012), comprovaram o efeito alelopático de extratos de diferentes órgãos de mulungu sobre a germinação de sementes de alface, observando o alto índice de plantas deformadas, com raízes necrosadas e alto percentual de plântulas mortas e não apresentando nenhuma normal.

Confrontando-se os resultados referentes ao tamanho do hipocótilo (Tabela 4), podese observar que o crescimento foi maior se comparado ao crescimento das radículas, tanto que as garrafadas 4 e 7 na concentração de 12,5\% apresentaram resultados semelhantes aos controles negativos, porém ainda verifica-se o efeito tóxico das garrafadas no desenvolvimento das sementes, visto que o efeito da maioria das concentrações é semelhante estatisticamente (valor- $p=0,0005)$ ao do sulfato de zinco.

Corroborando com esse resultado, o aumento da concentração de extrato de Persea venosa promoveu um efeito negativo ao comprimento das raízes mais significativo, do que ao comprimento da parte aérea do milho em trabalho realizado por Mendes et al. (2013). Estudo avaliando o potencial alelopático de extratos orgânicos das folhas de Pyrostegia venusta sobre sementes de pepino, evidenciou que o comprimento do hipocótilo foi afetado pelos extratos hexânico e metanólico, apresentando efeitos inibitórios sobre o crescimento da parte aérea da planta (Silva et al., 2011).

As garrafadas apesar de serem produtos artesanais de muito sucesso na cultura popular, não possuem estudos que comprovem sua confiança e eficácia, sendo necessária a realização de testes para verificação de sua segurança. Sendo assim, as garrafadas analisadas por serem industrializadas devem ter seguir critérios preconizados pela ANVISA
(Brasil, 2010) na avaliação de sua efetividade. Ao observar os rótulos das mesmas constata-se que as informações transmitidas são insuficientes, dificultando a identificação das plantas medicinais, suas partes botânicas e concentrações utilizadas no preparo, o que não assegura a sua confiabilidade. de 2014:

Segundo a Resolução $n^{\circ} 26$, de 13 de maio

São considerados produtos tradicionais fitoterápicos os obtidos com emprego exclusivo de matérias-primas ativas vegetais cuja segurança e efetividade sejam baseadas em dados de uso seguro e efetivo publicados na literatura técnicocientífica e que sejam concebidos para serem utilizados sem a vigilância de um médico para fins de diagnóstico, de prescrição ou de monitorização (Brasil, 2014).

Os produtos tradicionais fitoterápicos serão autorizados por meio da comprovação do uso seguro no ser humano por um longo período.

A RDC $n^{\circ} 26 / 14$ dispõe sobre o registro ou notificação de tais produtos e a adequação de sua rotulagem e com base nela foram examinados os rótulos das garrafadas pesquisadas e os dados obtidos estão discriminados na Tabela 5.

Embora as garrafadas tiverem sido fabricadas (2012-2013) antes desta resolução entrar em vigor e os dados disponibilizados em seus rótulos estarem em desacordo com o exigido por este documento, é importante averiguar a importância das informações contidas nos rótulos considerando que a rotulagem é de extrema importância não exclusivamente pelo caráter formal, mas pelo seu poder de informação e influência sobre o usuário (Petrovick et al., 2004).

De acordo com a RDC $n^{\circ} 26 / 14$, para que sejam consideradas produtos tradicionais farmacêuticos devem comprovar seu uso seguro e efetivo no ser humano por 30 anos ou presença na

TABELA 4. Valores médios para comprimento do hipocótilo $(\mathrm{mm})$ de sementes de alface (Lactuca sativa L,) segundo as concentrações das amostras das garrafadas comercializadas no Mercado Municipal de Montes Claros, MG, Brasil, 2014.

\begin{tabular}{llllllllll}
\hline \multirow{2}{*}{ Garrafada } & \multicolumn{7}{c}{ Concentrações das Amostras } & \multicolumn{7}{c}{ Controles } \\
\cline { 2 - 9 } & $12,5 \%$ & $25 \%$ & $50 \%$ & $75 \%$ & $100 \%$ & CNAD & CNAT & CNAM & CP \\
\hline 1 & $7,87 \mathrm{~d}$ & $4,41 \mathrm{c}$ & $0,15 \mathrm{a}$ & $0,00 \mathrm{a}$ & $0,00 \mathrm{a}$ & & & & \\
2 & $1,78 \mathrm{~b}$ & $0,00 \mathrm{a}$ & $0,00 \mathrm{a}$ & $0,00 \mathrm{a}$ & $0,00 \mathrm{a}$ & & & & \\
3 & $1,61 \mathrm{~b}$ & $0,45 \mathrm{a}$ & $0,00 \mathrm{a}$ & $0,00 \mathrm{a}$ & $0,00 \mathrm{a}$ & & & & \\
4 & $13,20 \mathrm{e}$ & $3,12 \mathrm{c}$ & $0,00 \mathrm{a}$ & $0,00 \mathrm{a}$ & $0,00 \mathrm{a}$ & $12,07 \mathrm{e}$ & $10,65 \mathrm{e}$ & $12,78 \mathrm{e}$ & $0,00 \mathrm{a}$ \\
5 & $2,80 \mathrm{c}$ & $1,75 \mathrm{~b}$ & $0,00 \mathrm{a}$ & $0,00 \mathrm{a}$ & $0,00 \mathrm{a}$ & & & & \\
6 & $0,00 \mathrm{a}$ & $0,00 \mathrm{a}$ & $0,00 \mathrm{a}$ & $0,00 \mathrm{a}$ & $0,00 \mathrm{a}$ & & & \\
7 & $11,55 \mathrm{e}$ & $7,86 \mathrm{~d}$ & $1,35 \mathrm{~b}$ & $1,00 \mathrm{a}$ & $0,00 \mathrm{a}$ & & & \\
8 & $0,00 \mathrm{a}$ & $0,00 \mathrm{a}$ & $0,00 \mathrm{a}$ & $0,00 \mathrm{a}$ & $0,00 \mathrm{a}$ & & & & \\
\hline
\end{tabular}

CV\% $=148,97 ;$ CNAD = controle negativo (água destilada); CNAT = controle negativo (água da torneira); CNAM = controle negativo (água mineral); $\mathrm{CP}=$ controle positivo (Sulfato de Zinco 1\%). Médias seguidas de mesma letra minúscula na linha não diferem entre si pelo teste de Scott-Knott a um nível nominal de significância de $5 \%$. 
TABELA 5. Dados exigidos pela RDC n² 26/14 para embalagem primária de produtos tradicionais fitoterápicos.

\begin{tabular}{|c|c|c|c|c|c|c|c|c|}
\hline \multirow{2}{*}{ Dados exigidos (RDC N²6/14) } & \multicolumn{8}{|c|}{ Garrafadas } \\
\hline & 1 & 2 & 3 & 4 & 5 & 6 & 7 & 8 \\
\hline Nome comercial & $x$ & $x$ & $x$ & $x$ & $x$ & $x$ & $x$ & $\mathrm{x}$ \\
\hline Nomenclatura popular & $x$ & $x$ & $x$ & $x$ & $x$ & $x$ & $x$ & $x$ \\
\hline \multicolumn{9}{|l|}{ Nomenclatura botânica } \\
\hline \multicolumn{9}{|l|}{ Concentração } \\
\hline \multicolumn{9}{|l|}{ Via de administração } \\
\hline Conteúdo & & & & & $x$ & & $x$ & \\
\hline \multicolumn{9}{|l|}{ Forma farmacêutica } \\
\hline Uso (adulto e/ou pediátrico) & $x$ & $x$ & $x$ & $x$ & & & $x$ & \\
\hline \multicolumn{9}{|l|}{ "Produto registrado com base no uso tradicional, não sendo recomendado seu uso } \\
\hline \multicolumn{9}{|l|}{ por período prolongado." } \\
\hline \multicolumn{9}{|l|}{ "Se os sintomas persistirem, procure orientação de um profissional de saúde." } \\
\hline \multicolumn{9}{|l|}{ Contraindicações } \\
\hline \multicolumn{9}{|l|}{ Cuidados de conservação } \\
\hline Nome e endereço completo & $x$ & $x$ & $x$ & $x$ & $x$ & & & $x$ \\
\hline CNPJ & $x$ & $x$ & $x$ & $x$ & $x$ & & & \\
\hline \multicolumn{9}{|l|}{ "INDÚSTRIA BRASILEIRA" } \\
\hline Nome e CRF do responsável & $x$ & $x$ & $x$ & $x$ & $x$ & & & $x$ \\
\hline \multicolumn{9}{|l|}{ SAC } \\
\hline Lote & $x$ & $x$ & $x$ & $x$ & $x$ & & $x$ & \\
\hline Fabricação & $x$ & $x$ & $x$ & $x$ & $x$ & & $x$ & \\
\hline Validade & $x$ & $x$ & $\mathrm{X}$ & $x$ & $\mathrm{x}$ & $\mathrm{X}$ & & $\mathrm{x}$ \\
\hline Código de barras & & & & & $\mathrm{x}$ & & & \\
\hline \multicolumn{9}{|l|}{ PRODUTO TRADICIONAL FITOTERÁPICO } \\
\hline \multicolumn{9}{|l|}{ "Produto Notificado na ANVISA nos termos da RDC n XX/XXXX" } \\
\hline \multicolumn{9}{|l|}{ "MANTER FORA DO ALCANCE DE CRIANÇAS" } \\
\hline “Informações ao paciente, posologia, modo de usar e efeitos indesejáveis: vide folheto & & & & & & & & \\
\hline informativo". & & & & & & & & \\
\hline
\end{tabular}

lista de produtos tradicionais fitoterápicos de registro simplificado, as drogas vegetais utilizadas devem estar descritas em farmacopeias autorizadas pela ANVISA, devem apresentar relatório de estabilidade, produção e controle de qualidade e além das informações exigidas nos rótulos das embalagens deverão vir acompanhadas de folheto informativo abrangendo todas as informações relevantes sobre o produto (Brasil, 2014).

Ressalta-se a relevância dos elementos abrangidos nos rótulos, entre outros dados, a indicação correta das espécies e não somente os nomes populares das plantas medicinais, o componente botânico e a concentração utilizada, auxiliariam para identificação do real efeito farmacológico e/ou possível toxicidade ao organismo.

A adequação das garrafadas garantirá a sua eficiência e segurança, transmitindo maior confiabilidade para os indivíduos que preferem utilizar o conhecimento tradicional em seus tratamentos. Após as análises realizadas conclui-se que os extratos vegetais contidos nas garrafadas demonstraram potencial alelopático ao inibirem a germinação das sementes de alface, não sendo possível determinar se é a presença de uma planta ou a interação entre as plantas que causou esse efeito; portanto, para verificar o possível efeito citotóxico e sua toxicidade em humanos serão necessários outros estudos, bem como os solicitados pela ANVISA, e cabe aos órgãos de fiscalização sanitária, monitorarem se as empresas estão se adaptando as novas leis e exigências, evitando, assim, riscos e danos à saúde da população.

\section{AGRADECIMENTO}

À Associação Educativa do Brasil SOEBRAS, pelo suporte financeiro a partir do Núcleo de Estudos em Plantas Medicinais - NEPM contemplado pelo Edital Universal SOEBRAS $1 \% 2013$. 


\section{REFERÊNCIAS}

ARAÚJO, A.S.F.; MONTEIRO, R.T.R. Plant bioassays to assess toxicity of textile sludge compost. Scientia Agricola, v.62, n.3, p.286-290, 2005.

ALVES, L.L. et al. Atividade alelopática de extratos aquosos de plantas medicinais na germinação de Lactuca sativa L. e Bidens pilosa L. Revista Brasileira Plantas Medicinais, v.13, n.3, p.328-36, 2011.

BONFIM, F.P.G. et al. Potencial alelopático de extratos aquosos de Melissa officinalis L. e Mentha $x$ villosa L. na germinação e vigor de sementes de Plantago major L. Revista Brasileira Plantas Medicinais, v.3, n.especial, p.564-68, 2011.

BRASIL. ANVISA. Agência Nacional de Vigilância Sanitária. Resolução RDC $n^{\circ} 26$ de 13 de Maio de 2014. Dispõe sobre o registro de medicamentos fitoterápicos e o registro e a notificação de produtos tradicionais fitoterápicos. Brasília: Diário oficial da União, n.90, p.52-61. 2014.

BRASIL. ANVISA. Agência Nacional de Vigilância Sanitária. Resolução RDC $n^{\circ} 14$ de 31 de Março de 2010. Dispõe sobre o registro de medicamentos fitoterápicos. Diário Oficial da República Federativa do Brasil, Brasília: Diário oficial da União, n.63, p.85-87. 2010.

BRASIL. Ministério da Agricultura, Pecuária e Abastecimento. Regras para análise de sementes. Ministério da Agricultura, Pecuária e Abastecimento. Secretaria de Defesa Agropecuária. Brasília, DF: Mapa/ ACS, 2009. 395p.

CAMARGO, M.T.L.A. A garrafada na medicina popular: uma revisão bibliográfica. Dominguezia, v.27, p.41-9, 2011.

CARREIRA, L.; SANTOS, C.F.M.do. Mezinhas, triagas e garrafadas: pequena reflexão histórica acerca da saúde e do cuidar no Brasil. Revista Ciências da Saúde, v.1, n.2, p.43-51, 2001.

DANTAS, V.S. et al. Análise das garrafadas indicadas pelos raizeiros na cidade de Campina Grande - PB. Revista de Biologia e Farmácia, v.3, n.1, p.7-13, 2008.

DE CONTI, D.; FRANCO, E.T.H. Efeito alelopático de extratos aquosos de Casearia sylvestris Sw. na germinação e no crescimento de Lactuca sativa L.. Revista Brasileira de Agrociência, v.17, n.2-4, p.193203, 2011.

FERREIRA, D.F. Análises estatísticas por meio do Sisvar para Windows versão 4.0. In: 45 ${ }^{a}$ REUNIÃO ANUAL DA REGIÃO BRASILEIRA DA SOCIEDADE INTERNACIONAL DE BIOMETRIA. 2000, São Carlos. Anais... São Carlos: UFSCar, 2000, p.255-58.

FRANÇA, I.S.X. et al. Medicina popular: benefícios e malefícios das plantas medicinais. Revista Brasileira de Enfermagem, v.61, n.2, p. 201, 2007.

MACHADO, J.M. et al. Curva de inibição para bioensaio de toxicidade aguda com sementes de alface utilizando o zinco In: $5^{\circ}$ SEMINÁRIO DE ENSINO, PESQUISA E EXTENSÃO DA FUNEDI/UEMG, 2009, Divinópolis. Anais... Divinópolis: FUNEDI/UEMG, 2009.

MAGIERO, E.C. et al. Efeito alelopático de Artemisia annua L. na germinação e desenvolvimento inicial de plântulas de alface (Lactuca sativa L.) e leiteiro (Euphorbia heterophylla L.). Revista Brasileira de Plantas Medicinais, v.11, n.3, p.317-24, 2009.

MENDES, C.E. et al. Avaliação do potencial fitotóxico de Persea venosa Nees \& Mart.(Lauraceae) sobre sementes e plântulas de diferentes espécies cultivadas. Revista Brasileira de Plantas Medicinais, v.15, n.3, p.337-46, 2013.

NASCIMENTO, I.L. et al. Influência de partes vegetais de Tamarindus indica L. como efeito alelopático na germinação da alface. Revista Agropecuária Científica no Semiárido., v.8, n. 4, p.97-101, 2012.

NOGUEIRA, A.J. Medicina Popular. 1.ed. Rio de Janeiro: Prefeitura Municipal, 2005. 49p.

NOLDIN, V.F. et al. Composição química e atividade biológica de Cynara scolymus L. cultivada no Brasil. Química Nova, v.26, n.3, p.331-4, 2003.

OLIVEIRA, A.K. et al. Alelopatia de extratos de diferentes órgãos de mulungu na germinação de alface. Horticultura Brasileira, v.30, p.480-3, 2012.

PELEGRINI, L.L.; CRUZ-SILVA, C.T.A. Variação sazonal na alelopatia de extratos aquosos de Coleus barbatus (A.) Benth. sobre a germinação e o desenvolvimento de Lactuca sativa L. Revista Brasileira Plantas Medicinais, v.14, n.2, p.376-82, 2012.

PETROVICK, G.F. et al. Análise da adequação da rotulagem de medicamentos industrializados. Infarma, v.16, n.7-8, p.54-8, 2004.

SILVA, P.B. et al. Avaliação do potencial alelopático, atividade antimicrobiana e antioxidante dos extratos orgânicos das folhas de Pyrostegia venusta (Ker Gawl.) Miers (Bignoniaceae). Revista Brasileira de Plantas Medicinais, v.13, p.447-55, 2011.

SIQUEIRA, C.F.Q.; HIGINO, J.S. Avaliação toxicológica crônica de garrafadas vendidas nas feiras livres da cidade de Caruaru - PE em camundongos. In: XVI CONIC - CONGRESSO DE INICIAÇÃO CIENTÍFICA DA UFPE, 2008. Anais... Pernambuco: UFPE, 2008.

SOUZA, C.S.M. et al. Alelopatia do extrato aquoso de folhas de aroeira na germinação de sementes de alface. Revista Verde de Agroecologia e Desenvolvimento Sustentável, v.2, n.2, p.96-100, 2007.

SOUZA, S.A.M. et al. Efeito alelopático de plantas medicinais nativas do Rio Grande do Sul sobre a germinação de sementes de alface. Ciências Biológicas e da Saúde, v.11, n.3, p.29-38, 2005.

SOUZA FILHO, R.Y. Garrafada: O saber popular e a abordagem CTS. 2011. 46p. Monografia (Graduação - Área de ensino em Química) - Instituto de Química, Universidade de Brasília, Brasília. 